\title{
$\mathbf{R}$

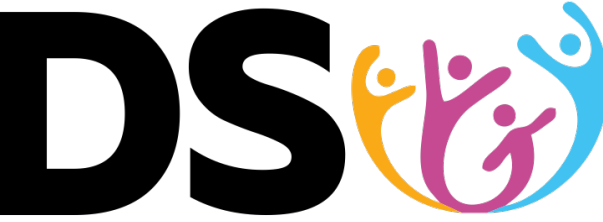

Revista Desenvolvimento Social

\section{ANALFABETISMO E EXCLUSÃO SOCIAL: APONTAMENTOS A PARTIR DO DIÁLOGO COM FREIRE, ARROYO, MARTA OLIVEIRA E ANTÔNIA}

\author{
Andréia Luciane Sol Souza ${ }^{1}$ \\ Alexandre Gonçalves ${ }^{2}$
}

\begin{abstract}
Resumo: Este texto marca o lugar da alfabetização como um "bem social" distribuído desigualmente na sociedade, na qual, as classes populares são desfavorecidas (FREIRE, 2008). O presente trabalho estabelece um "diálogo" entre Paulo Freire, Miguel Arroyo, Marta Oliveira e Antônia - mulher negra, trabalhadora e não alfabetizada. Este texto aponta a relação existente entre o analfabetismo e a exclusão social analisando o contexto e a vida da Antônia, em suas conexões com a educação de jovens e adultos e na implicação dos desafios teóricosmetodológicos para tratar desse tema. Um diálogo entre a educanda Antônia, sua trajetória de vida inseridas no contexto mais amplo do analfabetismo e as ações de educação popular. Assim, trazer elementos que possam contribuir com a compreensão das situações colocados às pessoas adultas não alfabetizadas ao lidar com ocasiões que são necessários o uso dos códigos de leitura e escrita. Neste sentido, convidamos aos (as) leitores (as) a refletir sobre a história de Antônia não como uma história individual, mas como uma história coletiva, que apresenta a realidade de muitas/os pessoas adultas não alfabetizadas.
\end{abstract}

Palavras-chave: Analfabetismo. Exclusão social. Freire. Educação de Jovens e Adultos (EJA). Antônia.

\section{ILLITERACY AND SOCIAL EXCLUSION: NOTES FROM THE DIALOGUE WITH FREIRE, ARROYO, MARTA OLIVEIRA AND ANTÔNIA}

Abstract: This text marks the place of literacy as a "social good" unevenly distributed in society, in which the popular classes are disadvantaged (FREIRE, 2008). The present work establishes a "dialogue" between Paulo Freire, Miguel Arroyo, Marta Oliveira and Antônia black, working and illiterate woman. This text points out the relationship between illiteracy and social exclusion, analyzing the context and life of Antônia, in its connections with youth and adult education and in the implications of theoretical-methodological challenges to deal with this theme. A dialogue between student Antônia, her life trajectory inserted in the

\footnotetext{
${ }^{1}$ Mestre em Educação e Inclusão Social (FAE/UFMG). Especialista em História e Culturas Políticas (FAFICH/UFMG). Graduada em História (PUC/MG). Pesquisadora colaboradora: "Homeopatia tecnologia social das famílias agrícolas e ambientes: formação de agricultores (as), transição agroecológica e contribuições à Educação do Campo" (Faculdade de Educação /UFV). Atua como assessora na Associação Estadual de Defesa Social e Ambiental de Minas Gerais (AEDAS/MG). E-mail: andreiasoll@gmail.com - ORCID: https://orcid.org/0000-0001-5857-7564.

${ }^{2}$ Doutorando em Antropologia Social (UFMG), Mestre em Administração na linha de pesquisa Gestão, Ambiente e Desenvolvimento (UFLA). Graduado em Agronomia (UFLA). Atua como agente da Comissão Pastoral da Terra. E-mail: alexandrecpt@gmail.com - ORCID: https://orcid.org/0000-0002-6157-9648.
} 
broader context of illiteracy and popular education actions. Thus, bring elements that can contribute to the understanding of situations placed to illiterate adults when dealing with occasions that require the use of reading and writing codes. In this sense, we invite readers to reflect on Antônia's story not as an individual story, but as a collective story, which presents the reality of many non-literate adults.

Keywords: Illiteracy. Social exclusion. Freire. Youth and Adult Education (EJA). Antonia.

\section{ANALFABETIZACIÓN Y EXCLUSIÓN SOCIAL: NOTAS DEL DIÁLOGO CON FREIRE, ARROYO, MARTA OLIVEIRA Y ANTÔNIA}

Resumen: Este texto marca el lugar de la alfabetización como un "bien social" distribuido de manera desigual en la sociedad, en la que las clases populares se encuentran en desventaja (FREIRE, 2008). El presente trabajo establece un "diálogo" entre Paulo Freire, Miguel Arroyo, Marta Oliveira y Antônia - mujer negra, trabajadora y analfabeta. Este texto señala la relación entre analfabetismo y exclusión social, analizando el contexto y la vida de Antônia, en sus conexiones con la educación de jóvenes y adultos y en las implicaciones de los desafíos teórico-metodológicos para abordar este tema. Un diálogo entre la estudiante Antônia, su trayectoria de vida insertada en el contexto más amplio del analfabetismo y las acciones de educación popular. De esta forma, aportar elementos que puedan contribuir a la comprensión de situaciones que se plantean a los adultos analfabetos cuando se enfrentan a ocasiones que requieren el uso de códigos de lectura y escritura. En este sentido, invitamos a los lectores a reflexionar sobre la historia de Antônia no como una historia individual, sino como una historia colectiva, que presenta la realidad de muchos adultos analfabetos.

Palabras clave: Analfabetismo. Exclusión social. Freire. Educación de Jóvenes y Adultos (EJA). Antonia.

\section{INTRODUÇÃO}

Mesmo que se possa conceituar o analfabetismo como uma questão de escassez educacional, insuficiência ou inexistência de escolaridade, é esta uma dentre as várias formas possíveis de definir o analfabetismo. Porém, é mais que isso. É sobretudo, um fenômeno de exclusão social e de subtração do gozo e dos benefícios sociais e dos direitos civis; de expressão da cultura erudita e paralelamente de desvalorização do popular e de seu próprio patrimônio cultural. (LEWIN, 1995).

A alfabetização no Brasil, só foi amplamente difundida no transcorrer do século XX. Para se ter uma ideia, no ano de 1900 as taxas de analfabetismo no país giravam em torno de 65,3\% do total da população. Carregando, desde o início, a marca da desigualdade e da negação de direitos, acumulamos uma dívida com homens e mulheres que não tiverem o acesso ao "bem social" da escrita (BARRETO, 1998).

Marcando o lugar da alfabetização como um "bem social", um bem distribuído de forma desigual entre as pessoas, prejudicando as classes populares, consequência 
de uma ordem social injusta, conformando-se, portanto, como uma questão de exclusão social (FREIRE, 2008).

Uma das facetas que expõe a complexidade da questão do analfabetismo pode ser verificada se olharmos para os dados que apresentam os índices do analfabetismo no mundo e no Brasil. A população atual do planeta é de aproximadamente 7,8 bilhões de habitantes. Entre eles, 774 milhões não são alfabetizados, isso representa, aproximadamente, $20 \%$ da população adulta, segundo dados da Organização das Nações Unidas para a Educação, Ciência e Cultura (UNESCO) divulgados em 2014.

No Brasil há aproximadamente 212 milhões de habitantes, deste total, segundo dados do Instituto Brasileiro de Geografia e Estatística (IBGE) divulgados em 2018 há cerca de 11 milhões de pessoas que não sabem ler e escrever. Se a educação é um campo marcado por desafios, no caso da Educação de Jovens e Adultos (EJA) ${ }^{3}$, mesmo com as inúmeras conquistas garantidas através da mobilização e da luta de educadoras (es) e educandas (os), essas adversidades são ainda mais marcantes.

A EJA é vista como uma forma para fazer frente à situação de exclusão e desigualdade social, sendo considerada como fundamental para a construção de uma sociedade mais justa e democrática. É também uma forma de assegurar os direitos humanos, a participação cidadã e a valorização da diversidade cultural.

Se a EJA ainda é vista, por muitos, como uma forma de possibilitar o acesso à Educação escolar àqueles que não tiveram a oportunidade de ir para a escola na infância ou que por algum motivo, tiveram que interromper seus estudos prevalecendo a ideia de uma atividade compensatória (SOARES, 1987), infelizmente, perpetua-se um discurso estigmatizado tanto em relação à problemática do analfabetismo quanto à pessoa não alfabetizada.

É urgente e necessário repensarmos a forma como tratamos a questão do analfabetismo no Brasil, compreendendo suas origens históricas e a conjuntura política, econômica e social que colocou treze milhões de pessoas na condição de

\footnotetext{
${ }^{3}$ Educação de Jovens e Adultos (EJA), para além de uma modalidade de ensino, é um campo político, que carrega consigo o rico legado da Educação Popular. "Os educadores e educadoras de pessoas jovens e adultas, assim como seus educandos (as), são sujeitos sociais que se encontram no cerne de um processo muito mais complexo do que somente uma "modalidade de ensino." (SOARES; GIOVANETTI; GOMES, 2011, p. 7)
} 
sujeitos não alfabetizados, os quais, além de não saber ler e escrever encontram-se à margem de seus direitos.

\section{QUEM SÃO AS PESSOAS ADULTAS NÃO ALFABETIZADAS NO BRASIL?}

A presente reflexão tem como foco analítico a condição das pessoas adultas não alfabetizadas, que compõem uma categoria social abrangente, a qual merece ser mais bem analisada e compreendida no contexto brasileiro.

Nos últimos anos, muitas pesquisas foram realizadas com o intuito de conhecer as especificidades da EJA e das pessoas que a compõem. Conhecer quem são estas pessoas é uma forma coerente para propor uma educação contextualizada que sirva realmente aos interesses das classes populares. Redimensionar os rumos da EJA para além de uma modalidade de ensino é conhecer as especificidades dos sujeitos concretos históricos que vivenciam os diferentes tempos da vida, assim avançar para superar visões restritivas (ARROYO, 2011, p. 22-23).

Pobreza e analfabetismo não se dissociam e a situação brasileira afirma isto, o Brasil apresenta uma das piores distribuições de renda entre ricos e pobres, segundo dados do Mapa do Analfabetismo no Brasil, (2003):

Em um País onde a renda dos $20 \%$ mais ricos é 32 vezes maior que aquela dos $20 \%$ mais pobres, a distribuição de educação e do analfabetismo não poderia ser diferente". (...) Enquanto a taxa de analfabetismo nos domicílios cujo rendimento é superior a dez salários mínimos é de apenas $1,4 \%$, naqueles cujo rendimento é inferior a quase $29 \%$. (BRASIL, 2003, p. $11)$.

Para contribuir com a identificação destes sujeitos, Marta Oliveira (2009) reitera em seus estudos sobre aprendizagem e conhecimento, a importância de conhecer os jovens e adultos da EJA. Segundo a autora, ao trabalhar com as temáticas que envolvem esses sujeitos, é necessário saber que não é apenas uma questão de faixa etária, mas de compreender as especificidades culturais que os cercam, sendo necessário estar ciente sobre a distinção entre esses sujeitos e os demais. Ela aponta que eles são, geralmente, pessoas que trazem em sua história quase nenhuma 
instrução escolar, na maioria das vezes são filhos e filhas de pais não alfabetizados e que chegam como migrantes às grandes metrópoles:

O adulto, para a Educação de Jovens e Adultos, não é o estudante universitário, o profissional qualificado que frequenta cursos de formação continuada ou de especialização, ou a pessoa adulta interessada em aperfeiçoar seus conhecimentos em áreas como artes, línguas estrangeiras ou música, por exemplo. Ele é geralmente o migrante que chega às grandes metrópoles provenientes de áreas rurais empobrecidas, filho de trabalhadores rurais não qualificados e com baixo nível de instrução escolar (muitos frequentemente analfabetos), ele próprio com uma passagem curta e não sistemática pela escola e trabalhando em ocupações urbanas não qualificadas, possuem experiência no trabalho rural na infância e adolescência, que busca a escola tardiamente para alfabetizar-se ou cursar algumas séries do ensino supletivo. (OLIVEIRA, 2009, p. 197-198).

Em consonância com Marta Oliveira (2009), entendemos neste trabalho a importância de apresentar quem são as pessoas da EJA e qual o lugar social que ocupam em nossa sociedade. Como aponta Arroyo,

não é qualquer jovem e qualquer adulto. São jovens e adultos com rosto, com histórias, com cor, com trajetórias sócio-étnico-raciais, do campo, da periferia (...) são jovens e adultos trabalhadores, pobres, negros, subempregados, oprimidos e excluídos" (ARROYO, 2006, p. 01).

Diante da realidade constatada na distribuição de renda, há ainda que se destacar a disparidade entre os números de pessoas não alfabetizadas moradores do campo e da cidade. Nas áreas rurais, “(...) um em cada quatro brasileiros com 15 anos ou mais, que vive no campo não sabe ler e escrever um bilhete simples." (GALVÃO; DI PIERRO, 2013, p.63).

Ciente do lugar de exclusão que marca a trajetória dos sujeitos da EJA, Brandão (2009) nos convida a retomar o sentido e o papel da educação popular e a realizar ações de fortalecimento das iniciativas populares, considerando a diversidade e a particularidade dos envolvidos para enfrentar as opressões e as restrições a eles impostas. 


\section{ADULTOS NÃO ALFABETIZADOS: PESSOAS DE APRENDIZAGEM E CONHECIMENTO}

Corroborando com a afirmação "adultos não alfabetizados são sujeitos de aprendizagem e de conhecimento" (OLIVEIRA, 2009, p. 137), apresentamos aqui importantes estudos realizados acerca do processo de aprendizagem de pessoas adultas e propomos o diálogo com pesquisadores que se debruçam sobre esta temática.

Paulo Freire (1996) é referência para o trabalho na alfabetização de adultos. Compartilhamos com ele a ideia de que, antes mesmo de ler a palavra, os adultos já fazem a leitura do mundo, homens e mulheres são confrontados o tempo todo com a necessidade de aprender e cada um constrói, de acordo com seus estímulos, às aprendizagens que Ihes cabem, sendo mediados pelo mundo e pelo outro. Para Freire, "aprender é uma aventura criadora, algo, por isso mesmo, muito mais rico do que meramente repetir a lição dada. Aprender para nós é construir, reconstruir, constatar para mudar, o que não se faz sem abertura ao risco e à aventura do espírito." (FREIRE, 1996, p. 77).

As primeiras experiências de Freire na alfabetização, a exemplo de Angicos, proporcionaram os círculos de cultura, espaços educativos e de diálogo, que promoviam o debate e a problematização sobre temáticas do cotidiano. Mais do que a pura decifração dos códigos da escrita, esperava-se que os sujeitos fossem capazes de ler a realidade em que estavam inseridos e, a partir daí, se mobilizassem para transformá-la. Era fundamental, nesse processo, que o sujeito criasse a consciência de que ele não era o responsável pela situação de exclusão e pobreza em que se encontrava e que o analfabetismo era um dos reflexos dessa situação. Freire preconizava ser necessário "tomar a alfabetização como consequência de uma ordem social injusta e, portanto, uma questão de natureza social e educacional" (BARRETO, 1998, p. 79).

Sujeitos em processo de alfabetização, quando orientados pela proposta freiriana, são motivados a ressignificar suas experiências e trajetórias com o intuito de dar um novo sentido aquilo que formatava sua experiência de vida, relacionando-a com amplos aspectos do mundo, criando, recriando e integrando-se às condições do 
seu contexto, respondendo aos seus desafios. Esse movimento lança homens e mulheres ao domínio que lhe é exclusivo: o da história e da cultura.

Outra importante estudiosa dos processos cognitivos de adultos das classes populares é Oliveira (2009). Ela ressalta que as pesquisas sobre o desenvolvimento da aprendizagem e da construção do conhecimento por adultos apresentam uma limitação considerável, já que os estudos sobre os processos cognitivos, em geral, estão muito voltados para as categorias da infância e juventude.

Sobre os processos de aprendizagem de adultos, a autora mostra que o fato de eles estarem inseridos no mundo do trabalho e desenvolverem diferentes relações interpessoais, diferentemente das crianças e dos adolescentes, faz com que tragam consigo uma história mais longa e muitas vezes mais complexa, além de uma maior capacidade de reflexão sobre o conhecimento e sobre seus próprios processos de aprendizagem (OLIVEIRA, 2009, p. 200-202).

Em estudo realizado sobre as competências cognitivas utilizadas no cotidiano por alunos da EJA, residentes numa favela de São Paulo, Oliveira mostrou que as pessoas aprendem a atuar cognitivamente nos ambientes específicos onde elas vivem e é nesses ambientes que elas desenvolvem tarefas importantes para seu processo de aprendizagem. Sobre isso, a autora nos revela que:

É no interior de um determinado meio doméstico e social que os seres humanos, quaisquer que sejam suas experiências prévias de aprendizagem e seu potencial biológico, tornam-se de fato capazes de operar cognitivamente em respostas às demandas desse meio particular e de acordo com o treinamento específico aí obtido. (OLIVEIRA, 2009, p. 105).

Essa constatação é importante, pois corrobora com a ideia de que adultos não alfabetizados são capazes de elaborar e articular os conhecimentos construídos para lidar com as situações cotidianas que a vida Ihes impõe. Mas, diante de uma sociedade tecnológica e letrada, são expostos muitos desafios devido à sua condição de não alfabetizados. 


\section{DESAFIOS VIVIDOS POR ADULTOS NÃO ALFABETIZADOS}

Isturdia fui no posto.

Pro dotô tirá um inzame, passei ôto vexame Cum vergonha de novo, Tava todo o povo Cum os zoião desse tamãe Butecado pra riba deu Só pruque esse besta dizia quinda num sabia Assiná de caneta. Tô me sintino um lixo, deferente de todo mundo, com esse dedo breado.

(Jota Neris, 2005)

Pessoas adultas não alfabetizadas são expostas diariamente a diferentes tipos de desafios quando estão diante de situações que necessitam do uso da leitura e da escrita e essas situações desafiadoras são agravadas devido à condição social que pertencem: são pobres, negros, mulheres, moradoras/es das periferias, vilas e favelas dos grandes centros urbanos; migrantes; camponesas/es, trabalhadoras/es que ocupam os cargos mais baixos hierarquicamente, entre outros aspectos.

Para muitas/os adultas/os que não sabem ler e escrever, o analfabetismo não é compreendido como um processo de exclusão social ou como violação de direitos, mas como "uma experiência individual de desvio ou fracasso, que provoca repetidas situações de discriminação e humilhação, vividas com grande sofrimento e, por vezes, acompanhadas por sentimento de culpa e vergonha." (GALVÃO; DI PIERRO, 2013, p. $15)$.

A ideia errônea de que as pessoas não alfabetizadas são seres "de menor valia", pode ser ilustrada através do trabalho realizado em momentos de formação do Programa Brasil Alfabetizado (PBA), onde Galvão e Di Pierro (2013) propuseram um desafio aos alfabetizadores do programa: elas pediram que os alfabetizadores do programa que participavam da formação registrassem a forma como viam as pessoas não alfabetizadas e o resultado recolhido pelas pesquisadoras foi o seguinte:

“(...) incapaz, incompleto, dependente, perdido, manobrado, cego, coitado, sofredor, despreparado, desumanizado, isolado, alienado, massa amorfa, 
aquém da sociedade, desinformado, fome, pobreza, classe dominada, exclusão, segregação, sem a acesso a direitos, discriminação, Brasil, preconceito." (GALVÃO; DI PIERRO, 2013. p. 9)

Diante de situações que demandam o uso da leitura e da escrita, muitos adultos não alfabetizados, temendo serem expostos à situações constrangedoras, acabam por viver de forma resignada e não associam criticamente o fato de não serem alfabetizados, a uma situação histórica de negação de direitos e exclusão social, sentindo-se muitas vezes responsabilizados socialmente pela sua condição.

Portanto, conhecer quem são estas pessoas nos convida a propor uma educação contextualizada que sirva realmente aos interesses das classes populares. Redimensionar os rumos da EJA para além de uma modalidade de ensino é conhecer as especificidades dos sujeitos concretos históricos que vivenciam os diferentes tempos da vida, avançando para superar visões restritivas (ARROYO, 2011, p. 22-23).

Diante dessa grave situação e contexto, e da imprescindibilidade das pessoas envolvidas, trazemos para o texto a história de Antônia.

\section{ANTÔNIA}

Quem lida com alfabetização sabe qual é a importância do nome para aqueles e aquelas que estão aprendendo a ler e escrever. Muitas vezes, é o desejo de assinar o próprio nome que faz com que homens e mulheres retornem aos estudos. Mais do que assinar e abandonar o constrangimento de "sujar o dedão", saber escrever o próprio nome é uma forma de refletir sobre sua existência no mundo.

Antônia é mineira, nasceu no município de São Sebastião do Maranhão, mulher, negra, viúva, mãe de quatro filhos, cedeu este relato quando era educanda de uma turma de alfabetização do Movimento de Alfabetização de Adultos (MOVA), na época estava com 53 anos. Ela relata que teve a infância marcada pelo trabalho doméstico; vivenciou a falta de acesso à moradia, à escola, saúde e transporte; teve sua vida marcada por tragédias e inúmeros reveses econômicos. Ela inicia seu relato trazendo à memória a infância vivida ao lado dos pais e sete irmãos, vida marcada pelo trabalho duro na lavoura e nos afazeres domésticos. Sobre esta passagem ela relata: 
"Meu pai trabalhava a semana toda, mexia com lavoura, e minha mãe ajudava ele a trabaiar. (...) Eu, com sete anos, tomava conta de três irmãos. Roupa eu não lavava porque não dava conta. Buscava água de tina. Fazia a comida. Dava banho nos meninos. Buscava fubá numa fazenda lá perto. Fubá de moinho. Arrumava a casa toda. Minha mãe ficava feliz". (Antônia)

Antônia conta que na região todos comentavam que ela era uma menina "trabaiadeira" e isso atraiu até sua casa um fazendeiro de Sete Lagoas que a convidou para ir embora com ele. De acordo com suas memórias:

\begin{abstract}
"Aí bateu na porta. Eu abri e era uma pessoa de Sete lagoas. (...) Aí ele falou assim: você dá seu nome???? pros outros? Dou. Sua mãe está em casa? Minha mãe tá trabaiando, só a noite que ela tá em casa. Aí ele falou assim: "Ocê quer ir embora com a gente? Eu tô procurando uma menina daqui pra morar comigo em casa, ficar lá, tomando conta, pra ser babá. Aí eu pensei na minha mãe.. longe da minha mãe não vai dar. Aí ele falou assim: Eu te dou tudo: sapato, roupa, escola. Aí, quando foi a noite, ele veio e falou com minha mãe. Aí minha mãe falou assim: "Óia! Essa menina é trabaiadeira, ela é responsável, ela que cuida dos meninos pra mim, pra eu poder trabaiar". Aí, já tinha o juiz de paz lá da minha cidade, um tal de Augusto Ribeiro, que era o juíz de paz que tinha naquele tempo, e aí esse homem tava ajeitando tudo pra me tomar da minha mãe. [choro]. Aí, eu não sabia não. Como minha mãe era separada / viúva eles tomavam os meninos da mãe, uns fugiam, outros iam embora, mas eu não tive como escapar...Eles aumentaram minha idade. Eu tinha dez anos, eles pôs doze. Pra mim foi a maior tristeza do mundo. Porque eles me tiraram da minha mãe e eu nunca mais vi ela". [choro]. (Antônia)
\end{abstract}

Relata que o que aconteceu na casa dessas pessoas foi bem diferente do que foi prometido, “(...) eu não gostava de ficar com esse pessoal porque eles eram ruins demais, eles só me dava comida, roupa e mais nada". A situação de Antônia reflete a de muitas outras crianças filhas das classes populares, que, espalhadas pelo Brasil, são privadas do convívio familiar e levadas a realizar todo tipo de trabalho. Enquanto "morava" com a família de fazendeiros em Sete Lagoas, ela chegou a ser matriculada em uma escola, mas disse que não conseguia aprender e nem se concentrar nas aulas, devido a separação dos pais e por causa do cansaço diário impingido pelo trabalho doméstico. Esse acontecimento acarretou em sua vida uma série de sofrimentos e traumas, inclusive, ela relaciona esse fato ao motivo de não ter conseguido se concentrar na escola e não ter conseguido se alfabetizar, segundo Antônia: 
"Eu fui...[para a escola] mas não conseguia concentrar mais. Eu tinha dez anos. Então, mas eu nunca consegui concentrar na escola, minha cabeça não firmava. Eu via as letras, mas eu ficava com aquela coisa na minha cabeça... devido à separação da minha mãe. Não consegui aprender a ler não. Até hoje a minha cabeça fica assim confusa. [tristeza]. Eu cheguei a ir na escola, eu cheguei a estudar aqui no bairro, um outro bairro que eu morava... mas eu não cheguei a aprender".

Antônia revela que durante toda sua vida, teve o desejo de aprender a ler e a escrever, porém sua condição não favoreceu para que isso acontecesse. Ela destaca que a condição de pobreza em que vivia com sua família, fez com que ao invés de frequentar a escola, teve que se dedicar ao trabalho doméstico e da lavoura. Relata também que ao se casar, ainda muito jovem, não teve o apoio do marido para frequentar a escola, o que mostra que o caso de Antônia não é um caso isolado, já que, muitas mulheres são impedidas pelos homens de estudar.

Olhar para as/os educandas/os da EJA considerando suas trajetórias de vida e não apenas suas trajetórias escolares, é um apelo que o educador Miguel Arroyo tem feito aos que lidam com a educação, por isso o apelo para que o relato de Antônia não seja entendido apenas como uma história individual, mas como uma história coletiva, que representa a realidade de muitos (as) mulheres e homens, sujeitos da EJA desse País.

\section{CONSIDERAÇÕES FINAIS}

Adultos não alfabetizados são expostos diariamente a diversos desafios por não serem alfabetizados, esta situação é agravada devido a condição social, a qual pertencem - são pessoas negras (os), moradoras (es) das periferias, trabalhadoras (es) informais, migrantes etc. Muitas vezes, essas pessoas são invisibilizadas socialmente e os diferentes saberes que possuem são desvalorizados. As pessoas adultas não alfabetizadas não dominam os códigos da leitura e da escrita, mas mostram habilidades, conhecimento e saberes que são construídos ao longo da vida.

O caso da Antônia aqui analisado demonstra uma complexa relação entre a não alfabetização e a sua trajetória de vida. O contexto das pessoas não alfabetizadas, suas 
trajetórias e as condições de sobrevivência controversas, devem compor não só o campo de pesquisa acadêmica, mas serem usados para problematizar os processos de construção do conhecimento nos espaços da EJA. Criando processos contextualizados. Críticos e com capacidade de propor mudança sócios políticas.

\section{REFERÊNCIAS}

ARROYO, Miguel G. Ofício de Mestre, Imagens e Auto-Imagens. Petrópolis, Rio de Janeiro. Vozes, 2000.

ARROYO, Miguel G. Educação de Jovens-Adultos: um campo de direitos e de responsabilidade público. In: SOARES, L., GIOVANETTI, M.A.G.C., \& GOMES, N.L. Diálogos na Educação de Jovens e Adultos. 1ạ ed. Belo Horizonte: Autêntica, 2011.

BARRETO, Vera. Paulo Freire para educadores. São Paulo: Arte \& Ciência, 1998.

BARRETO, José. BARRETO, Vera. (1990). A formação de alfabetizadores. In: GARCIA, Pedro et al. Cadernos de Educação Popular, n. 17. Petrópolis, RJ: Vozes/Nova. p.54-61.

BRASÍLIA. Mapa do Analfabetismo no Brasil. MEC/INEP, 2003.

FREIRE, Paulo. Educação Como Prática da Liberdade. 31. ed. São Paulo: Paz e Terra, 2006. p. 158.

FREIRE, Paulo. Política e Educação. 4ạ ed. São Paulo: Cortez Editora, 2000.

FREIRE, Paulo. Pedagogia do Oprimido. 45a. ed. São Paulo: Paz e Terra, 2008.

GALVÃO, Ana Maria de Oliveira; DI PIERRO, Maria Clara. Preconceito contra o analfabeto. São Paulo: Cortez, 2013- (Preconceitos v. 2).

NERIS, Jota. Dedo Lambuzado: poemas e causos sertanejos. Vitória da Conquista: [s.n.], Brasil Artes Gráficas LTDA. 2005.

OLIVEIRA, Marta Kohl. Analfabetos na sociedade letrada: diferenças culturais e modos de pensamento. São Paulo: Travessia, v. 5, n. 12, pp. 17-20, jan. /abr. 1992.

OLIVEIRA, Marta Kohl. Questões sobre o desenvolvimento do adulto. São Paulo, 2009: ed. HUCITEC. 1998. p.490.

RIBEIRO, Vera Masagão. Alfabetismo e atitudes: Pesquisa com jovens e adultos. Campinas, SP: Papirus, 1999. 4 edições 2009.

SOARES, Leôncio (Org.); et al. Diálogos na educação de jovens e adultos. 4ed. Belo Horizonte: Autêntica, 2011. 296p.

TORRES, Rosa, M. Ações nacionais de alfabetização de adultos na América latina: uma revisão crítica. In: GARCIA, Pedro et al. Cadernos de Educação Popular, n. 17. Petrópolis, RJ: Vozes/Nova. 1990. p.09-23 